\title{
Optimization of Wood Fibre Refining Process in Fibreboard Production with New Refiner Disc Working Surface Geometry
}

\begin{abstract}
Aleksandr Vititnev, ${ }^{\mathrm{a}}$ Natalia Chistova, ${ }^{\mathrm{a}, \mathrm{b}}$ Yuri Alashkevich, ${ }^{\mathrm{a}}$ Venera Matygulina, ${ }^{\mathrm{a}}$ and Roman Marchenko ${ }^{\text {a }}$

Refining of fibrous semi-finished products is an important stage in fibreboard production because the efficiency of this stage affects the resulting fibres' dimensional and qualitative characteristics. These, in turn, determine the physical and mechanical properties of the finished products, as well as the energy intensity of the process. The efficiency of this process depends on the raw materials used and the geometry of the refiner disc working surface and its operational modes. This article presents the results of the optimisation of wood fibre refining at a low concentration (2 to $4 \%$ ), using fundamentally new refiner discs in high-density fibreboard production. Based on numerous theoretical and experimental studies, and on the results of processing, the problem of optimising the refining process was solved, taking into account the use of new refiner disc geometry. As a result, the optimal values of refiner process parameters and operation modes making it possible to prepare wood-fibre semi-finished products efficiently while reducing power consumption in refining were established. After optimising the refining process, the new geometry of refiner disc working surfaces provides optimal dimensional and qualitative characteristics of wood fibres, which results in finished products with high physical and mechanical properties in accordance with GOST 4598 (2018) without using bonding resins.
\end{abstract}

Keywords: Refining; Refiner disc geometry; Fibrillation; Wood-fibre semi-finished product; Fibreboards; Optimization

Contact information: a: Reshetnev Siberian State University of Science and Technology 31, Krasnoyarskii Rabochii Prospect, Krasnoyarsk 660037, Russian Federation; b: Krasnoyarsk Railway Transport Institute, branch of Irkutsk State Transport University, 2g, Novaya Zarya Street, Krasnoyarsk, 660028, Russian Federation;*Corresponding author: sanekvititnev@yandex.ru

\section{INTRODUCTION}

In addition to equipment downtime due to mechanical failures, the main causes of losses incurred in board production include the instability of process equipment modes, the quality of initial raw materials and finished products, and the absence of optimal operation modes of process areas for fibreboard production (Matygulina et al. 2011).

Many studies have focused on issues related to stabilising operation conditions and increasing equipment performance at the board product pressing stage (Gao et al. 2011; Li et al. 2019). Researchers have studied various sizing and binding agents, their influence on the physical and mechanical properties of finished products, and their environmental aspects (Mancera et al. 2011; Gao et al. 2011; Song et al. 2018; Li et al. 2019; Park et al. 2020).

In the production of fibreboards and fibrous materials such as paper, cardboard, etc., one of the most important and energy-intensive process stages is wood fibre refining. 
Refining is usually carried out in devices where refiner discs are the main working elements. Bars are located on a plate in a pattern specified by bar width/groove width/groove depth, and bar angle. During refining, refiner disc bars intersect, affecting the wood fibres, which consequently ensures their destruction both in the longitudinal (fibrillation) and transverse (shortening) directions. The nature of fibre breaking during refining determines the fibres' qualitative characteristics and composition, which directly affects the properties of finished products (Gao et al. 2011; Badin et al. 2018; Gao et al. 2018; Zhang et al. 2019; Cai et al. 2020; Przybysz et al. 2020). Refining intensity is determined largely by the geometric dimensions of processed fibres and the species composition of wood raw materials (Berg et al. 2009; Li et al. 2011; Rusu et al. 2011; Hua et al. 2012; Sable et al. 2017; Benthien et al. 2017; Gurau et al. 2017, Badin et al. 2018; Gao et al. 2018; Dickson et al. 2020; Fredrikson and Paltakari 2020; Przybysz et al. 2020). Wood fibre quality indicators (degree of refining, average length and diameter, length-to-diameter ratio) and refining effectiveness depend on many design (geometric properties of refiner disc working surfaces) and process parameters (working gap between refiner discs, pulp concentration, rotor frequency, etc.) (Li et al. 2011; Gao et al. 2018).

An increase in the rotor frequency contributes to the fibrillation of fibres while maintaining their length and reducing power consumption (Somboon et al. 2008). Previous research has shown that an increase in pulp concentration during refining improves fibre quality and refiner performance (Goncharov 1990; Smith 1992; Huber et al. 2008; Alashkevich et al. 2010; Olejnik 2013). Regulation of a working gap between refiner discs (specific pressure) significantly affects the nature of changes in wood fibre geometric dimensions (Goncharov 1990; Bordin et al. 2008; Gao et al. 2011; Kerekes 2011; Li et al. 2011; Benthien et al. 2017).

Most studies of the refining process have focused on optimising processing modes to reduce power consumption (Gao et al. 2011; Hua et al. 2012; Olejnik et al. 2013; Pelletier et al. 2013; Min et al. 2020).

The geometrical properties of refiner disc working surfaces (angle of bars, their width and the width of the inter-knife groove, etc.) primarily determine the nature and intensity of fibre breaking in the longitudinal (fibrillation) and transverse (shortening) directions (Nabieva 2004; Bordin et al. 2007; Kovalev 2007; Vikharev 2019; Cai et al. 2020; Liu et al. 2020). Some studies have described the effect of knife width and how densely they are located on discs, the sharpness of their edges, disc parallelism, and disc working surface roughness on the characteristics of fibres obtained in refiners (Bordin et al. 2007; Bordin et al. 2008; Somboon et al. 2008; Alashkevich et al. 2010; Fernandez et al. 2018; Cai et al. 2020).

Examination of cellulosic fibre refining at low concentration has confirmed that the process efficiency and the quality of fibrous semi-products are more dependent on the design properties of refiner disc working surfaces and processing modes (Gao et al. 2011; Cai et al. 2020; Fredrikson and Paltakari 2020; Liu et al. 2020; Min et al. 2020).

Many types of refiner disc working surface designs have been developed for processing cellulose fibres (Nabieva 2004; Kovalev 2007; Alashkevich et al. 2010; Kozhukhov 2015; Liu et al. 2020, Cai et al. 2020). However, there is practically no scientific approach to the design, manufacture, and effective use of refining equipment and its working elements for certain existing conditions of refining wood plant raw materials. The geometry of refiner disc working surfaces has remained the same in fibreboard production for many years, including at the wood fibre refining stage. The quality of the raw material base for the production of wood fibre materials is deteriorating. 
Mainly sawmill waste is used, but the use of biomass waste and various plant raw materials is expanding, which affects the qualitative characteristics of wood fibre semi-finished products differently. Therefore the use of the traditional refiner disc geometry may be inappropriate.

Evidence-based solutions are required for the development and creation of new refining equipment meeting the requirements for the finished product quality while ensuring the high efficiency of the milling of wood fibre semi-finished products using wood raw materials of various types and quality, including off-spec ones (Muller et al. 2009; Gao et al. 2011; Lubke et al. 2014; Zhao et al. 2018; Ihnat et al. 2017; Gao et al. 2018; Ihnat et al. 2018; Ammar et al. 2018; Irle et al. 2018; Ihnat et al. 2020; Min et al. 2020).

The results of the experiment conducted under production conditions as close as possible to the fibreboard production process confirm the high efficiency of using the new design of refiner disc working surfaces, all other conditions for wood fibre refining being the same (Vititnev 2019).

Analysis of different works (Matygulina et al. 2011) and the use of new refiner discs in industrial conditions require a solution to the problem of optimising wood fibre refining when establishing optimal qualitative characteristics of fibres, design, process, and mode-related parameters of the process to obtain high-quality finished products with minimum power consumption meeting national standards.

This article presents the results of optimising the refining process using a new refiner disc design to ensure wood fibre refining and efficient refining equipment function.

\section{EXPERIMENTAL}

After numerous theoretical and experimental studies (Nabieva 2004; Alashkevich et al. 2010; Chistova 2010; Zyryanov 2012; Vititnev 2019), a fundamentally new geometry of refiner disc working surfaces was developed using the modern MATLAB (version 6.13, MathWorks, Inc., Natick, MA, U.S.A ), KOMPAS-3D (V12, Ascon, Saint-Petersburg, Russian Federation), and Statistica 6.0 (version 6.0, StatSoft, Inc., Tulsa, OK< U.S.A) software packages.

\section{Theoretical Study Methods}

The main process parameters (length of cuts per second $\left(L_{s}, \mathrm{~m} / \mathrm{s}\right)$; number of intersection points (contacts) for rotor and stator bars $(t$, pcs.); cyclic elementary length $\left(L_{\omega . e l}, \mathrm{~m}\right)$; refining surface $\left.\left(F, \mathrm{~m}^{2}\right)\right)$ of the new refiner disc geometry developed were calculated using published methods reported in the literature (Nabieva 2004; Kovalev 2007), taking into account the use of transparent rotor and stator disc models. Transparent disc models were made using the toolbar of the modern KOMPAS-3D V16 application package based on certain features of design solutions for the working surface: bar width $(\delta$, $\mathrm{mm})$ and inter-bar groove width $\left(L_{\text {int.d. }}, \mathrm{mm}\right)$, setting angles of the rotor and stator bars $\left(\alpha_{1,2}\right)$, repetition angle of the pattern $\left(\Psi,{ }^{\circ}\right)$, number of sectors $(2 \pi / \psi$, pcs. $)$, the crossing angles of the rotor and stator knives $\left(\alpha_{\mathrm{cr}},{ }^{\circ}\right)$ (Fig. 1).

The true length of cuts per second and the number of simultaneously moving tool intersection points were determined in the software programme (Nabieva et al. 2009) developed using the modern Matlab application package. 


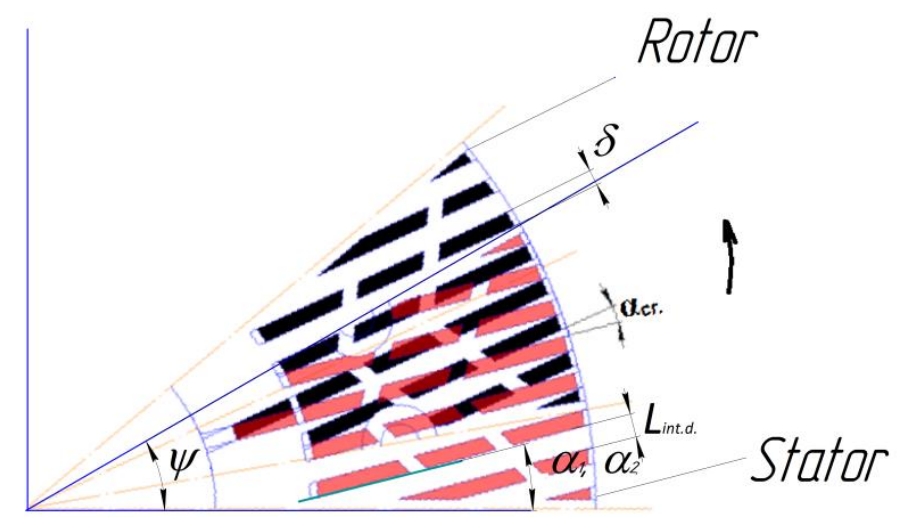

Fig. 1. Transparent rotor and stator disc models (single sectors) new refiner disc geometry

The process parameter $\left(L_{\omega . e l}, \mathrm{~m}\right)$, was determined using to Eq. 1,

$$
L_{\omega . e l .}=\frac{L_{S} \cdot 60}{n \cdot t \cdot(2 \pi / \psi)}
$$

where $t$ is the number of moving intersection points of rotor and stator bars (pcs.), $n$ is the rotor frequency (rpm), and $2 \pi / \psi$ is the number of sectors.

The formula cyclic elementary length $\left(L_{\omega . e l}, \mathrm{~m}\right)$ in addition to the length of cuts per second, the formula takes into account the number of moving points (contacts) formed with the cutting edges being intersected, which is an essential value that forms the cyclic elementary length of the refiner discs. This parameter, together with the length of cuts per second and the number of moving points (contacts), allows to more objectively characterise the effectiveness of refiner discs towards shortening fibres or obtaining long-fibre fraction with fibrillation.

Several works (Nabieva 2004; Kovalev 2007; Kozhukhov 2015) show that the indicator $\left(L_{\omega . e l}, m\right)$ decreases with an increase in $(t, p c s$.$) , which increases the shortening$ effect and worsens refining quality, as well as decreases refiner performance.

The refining surface $\left(F, \mathrm{~m}^{2}\right)$ was determined using KOMPAS-3D V16 tools with transparent rotor and stator disc models being coupled.

\section{Methods for Conducting Experimental Studies}

Mathematical planning methods were used for these studies. Based on many preliminary studies of the wood fibre refining process, it has been established that the process can be mathematically described with second order polynomials.

To carry out experimental studies, according to the well-known methods (Pen and Mencher 1978; Pizhurin 2005), a three-factor experiment based on the second order B-plan was chosen to assess the effect of the refining process on the dimensional and qualitative characteristics of wood fibres using new refiner disc geometry (Vititnev 2019).

After the primary refining of industrial chips using the RT-50 defibrator, wood fibres TMM were used as raw materials under study various degrees of refining $\left(Q_{\mathrm{d} 1}\left(\mathrm{DS}_{\mathrm{d}}\right)\right.$ $=10 \mathrm{DS} ; L_{\mathrm{a}}=8.67 \mathrm{~mm} ; Q_{\mathrm{d} 2}\left(\mathrm{DS}_{\mathrm{d}}\right)=12 \mathrm{DS} ; L_{\mathrm{a}}=6.85 \mathrm{~mm} ; Q_{\mathrm{d} 3}\left(\mathrm{DS}_{\mathrm{d}}\right)=13.5 \mathrm{DS} ; L_{\mathrm{a}}=8.67$ $\mathrm{mm})$. The chips were obtained from sawmill waste and low-quality wood from the raw material yard, mixed softwood $(99 \pm 1) \%$, mainly from Siberian pine, which corresponds to GOST 15815 (83) Process Chips. Specifications. The raw materials were provided by the fibreboard plant of the Lesosibirsky LDK No. 1 Company of Segezha Group.

Experimental studies of wood fibre refining were carried out using the resources of 
the laboratory of the Department of Industrial Technology and Machine Engineering of Reshetnev Siberian State University using a MD semi-industrial single-disc refiner at low concentration and with the developed geometry of fibrillation refiner discs (Vititnev 2019) while changing the main design and process parameters of the refining process under conditions as close as possible to production ones. Such operations as pulp gluing, mattress forming, and finished product pressing were carried out at the Central Laboratory of the Lesosibirsky LDK No. 1 company of Segezha Group. All other conditions for fibreboard production were kept the same. As a result, the physical and mechanical properties of finished boards were assessed, in particular the static bending strength $\left(\sigma_{i}, \mathrm{MPa}\right)$, density $\left(\rho, \mathrm{kg} / \mathrm{m}^{3}\right)$, and water absorption for $24 \mathrm{~h}(\mathrm{~A}, \%)$.

In the multifactor experiment process, after refining wood fibres under certain process and design parameters, their dimensional and qualitative characteristics were assessed, such as degree of refining (DS), fraction composition $\left(F_{1}, F_{\mathrm{m}}, F_{\mathrm{f}}, \%\right)$, average length $\left(L_{\mathrm{a}}, \mathrm{mm}\right)$, average diameter $\left(d_{\mathrm{a}}, \mathrm{mm}\right)$, fibrillation index $(\mathrm{Fbr})$, and length-to-diameter ratio $\left(L_{\mathrm{a}} / d_{\mathrm{a}}\right)$.

In addition to the experimental parameters under study, the following input and output parameters presented in Table 1 were used to solve the optimisation problem.

Table 1. Experiment Input and Output Parameters

\begin{tabular}{|c|c|}
\hline Parameter & Designation \\
\hline \multicolumn{2}{|c|}{ Input parameters (controllable factors) } \\
\hline Working gap width, mm & $g$ \\
\hline Pulp concentration, \% & $\mathrm{C}$ \\
\hline Degree of refining (defibrator), DS & $\mathrm{Qd}_{\mathrm{d}}(\mathrm{DS} \mathrm{d})$ \\
\hline Output parameters (controllable factors) \\
\hline Wood-fibre semi-product refining degree, DS \\
\hline Fibrous semi-product fibrillation index, \% & $\mathrm{DS}$ \\
\hline Average fibre length, mm & $\mathrm{Fbr}$ \\
\hline Fibre length-to-diameter ratio & $L_{\mathrm{a}}$ \\
\hline Average fibre fraction content in total pulp mass, \% & $L_{a} / d_{a}$ \\
\hline Specific power consumption for refining, $\mathrm{kW} \cdot \mathrm{h} / \Delta \mathrm{DS} \cdot \mathrm{t}$ & $\mathrm{F}$ \\
\hline
\end{tabular}

Based on many theoretical and experimental studies (Chistova 2010; Matygulina et al. 2011; Zyryanov 2012; Vititnev 2019) using new refiner disc geometry, and after processing the obtained results taking into account the refining design and process parameters, the following functional dependencies were obtained: DS, Fbr, $\mathrm{L}_{\mathrm{a}}, \mathrm{L}_{\mathrm{a}} /_{\mathrm{da}}, \mathrm{F}_{\mathrm{m}}, \mathrm{E}=\mathrm{f}\left(Q_{d}\left(\mathrm{DS}_{\mathrm{d}}\right), \mathrm{g}, \mathrm{c}\right)$.

\section{Processing of Research Results}

The experimental results were processed using the STATISTICA-6 application package (Borovikov and Borovikov 1998). Experimental data processing produced statistical and mathematical models with natural factor designations describing the refining process adequately. The models obtained made it possible to establish the quantitative dependencies of dimensional and qualitative characteristics of wood fibres on process parameters using new refiner disc geometry, in particular, for optimising the refining process and its further operation in industrial conditions (Vititnev 2019). 
The models obtained were adequate at a confidence level of 95 to $99 \%$. The coefficient of determination values $\left(\mathrm{R}^{2}\right)$ were close to one. The model coefficients were estimated using the method (Borovikov and Borovikov 1998; Pizhurin 2005) and the Student's t-test, and their significance was stated. Verification of the models using the Fisher's F-test showed them to be adequate.

\section{Method for Determining the Dimensional and Qualitative Characteristics of Wood Fibres, Specific Power Consumption for Refining, Finished Product Physical, and Mechanical Properties}

The degree of refining of wood-fibre pulp was determined using the DefibratorSecond device by the Sunds-Defibrator company (Stockholm, Sweden) used in fibreboard production. The methods involve dewatering (10 1) of pulp containing $128 \mathrm{~g}$ of oven dried fibers (O.D.). The operation principle of this device is based on different water yield characteristics of the fibrous suspension depending on its processing degrees. The dewatering time (in seconds) is expressed by measurement units of the degree of refining (DS). The obtained result is corrected according to a nomogram taking into account the ratio of the actual amount of O.D. in pulp to the standard amount for the device (Mersov 1989; Chistova 2010; Zyryanov 2012).

The fibrillation index of wood fibres characterises the intensity of their development and the presence of internal and external fibrillation. These factors determine their binding ability, as well as their content in the total mass of semi-finished products (expressed as a percentage). The mean fibre fibrillation was determined by visual estimation of at least 100 fibres per sample through microscopic measurement using a Hitachi SU-3500 microscope (Tokyo, Japan) with 3,000x magnification.

Fractional composition of semi-finished product $\left(\mathrm{F}_{\mathrm{l}}(>4 \mathrm{~mm}), \mathrm{F}_{\mathrm{m}}(4-1.5 \mathrm{~mm}), \mathrm{F}_{\mathrm{f}}\right.$ $(1.5-0.04 \mathrm{~mm}), \%)$. The fibre fractioning device filters a certain amount of wood fibres through sieves with cell sizes corresponding to the qualitative assessment categories (Laskeev 1967; Chistova 2010; Zyryanov 2012). After fractioning, these fibres collected from the sieves were weighed separately, and the weight of every fraction was expressed as a percentage of the total pulp content.

In the fraction separation of fibrous semi-finished products on the FVG-2 fractionator, the wood fibre lengths and diameters were measured by microscopic measurement using a Hitachi TM-3000 digital microscope with a 3,000x magnification. The fibres were then classified into different fractions (Laskeev 1967; Chistova 2010; Zyryanov 2012).

The average fibre length $\left(L_{\mathrm{a}}, \mathrm{mm}\right)$ and diameter $\left(d_{\mathrm{a}}, \mathrm{mm}\right)$ indicators characterise the wood fibre breaking, and their ratio $\left(L_{\mathrm{a}} / d_{\mathrm{a}}\right)$ characterises the intensiveness of change in the longitudinal and transverse directions, thereby determining, to a greater extent, the fibres' specific surface and flexibility. The geometrical indicators were determined using a well-known method (Laskeev 1967; Chistova 2010; Zyryanov 2012; Ferritsius et al. 2018) for assessing at least 100 fibres per sample by calculating the arithmetic mean length and diameter values and their ratio.

During wood fibre refining under various modes in line with the experimental procedure, the refiner specific power consumption $(E, \mathrm{~kW} \cdot \mathrm{h} / \Delta \mathrm{DS} \cdot \mathrm{t})$ was determined to using to Eq.2,

$$
\left.\mathrm{E}=\left(\mathrm{N} \cdot \mathrm{t}_{\mathrm{r}}\right) / \Delta \mathrm{DS} \cdot \mathrm{t}\right)
$$

where $N$ is power consumption $(\mathrm{kW}), t_{r}$ is the refining time (h), $t$ is the absolutely dry fibre weight $(\mathrm{t})$, and $\triangle D S$ is the difference in the degree of refining before and after refining. 
The physical and mechanical properties of finished fibreboards were assessed in accordance with GOST 4598 (2018), EN 622 (2004), and GOST 10633 (2018).

\section{Methods for Solving the Optimisation Problem}

When solving the problem of optimising the refining process, all factors must be considered based on their effect on the solution of three main problems: increasing the efficiency of wood-fibre semi-finished product preparation process; obtaining an amount of working press pulp of the required quality; and rational power consumption (Matygulina et al. 2011).

Some factors can positively affect each of the three final results, while others do so in opposite directions. It is therefore important to choose an optimal combination of the influence of all factors on the process under study, taking into account the use of new refiner disc geometry.

During the study, to optimise the refining process, it is necessary to identify missing data for building and analysing the optimisation data model; this makes it possible to quickly control the technological process to obtain its highest efficiency (Matygulina et al. 2011). The optimisation model of the refining process must represent a set of specific variables characterising the quantity and quality of input factors of the wood raw material preparation process, as well as influencing factors that help to purposefully control an object by changing the position of regulatory bodies, the refiner design, and process parameters (Pizhurin 2004; Chistova 2010).

When choosing a function, the objectives were guided by the principle of singlevaluedness, according to which one objective function is minimised or maximised, which must be expressed through process control variables, be single-valued and have one extremum.

The choice of a criterion for optimising the refining process is important for the subsequent use of the results in practice, in the production process. Therefore, it must fully and accurately describe the objective and equally have a fairly simple solution to the relevant mathematical problem (Pen and Mencher 1978; Balmasov 1979).

As an integral optimisation criterion, the efficiency of wood fibre refining in the refiner was chosen, taking into account the refiner disc surface geometry.

The main indicator of wood fibre refining efficiency is its quality. It was established that the degree of refining (DS) and the fibrillation index $\left(F_{\mathrm{br}}\right)$ determining the intensity and amount of fibres developed in the total mass of semi-finished products, the fibre lengthto-diameter ratio $\left(L_{\mathrm{a}} / d_{\mathrm{a}}\right)$, their average length $\left(L_{\mathrm{a}}\right)$, and the ratio of fractions in the total volume with a predominance of middle fractions $\left(F_{\mathrm{m}}\right)$ contribute to interfibre bonds and board structure formation.

Wood-fibre semi-finished products are assessed through several indicators, and according to the methods using the criterion convolution method, a generalised indicator $\left(Q_{\mathrm{f}}\right)$ was formed as a weighted sum of partial criteria (Pizhurin 2004, 2005),

$$
Q_{f}=\lambda_{1} \cdot w_{1}+\lambda_{2} \cdot w_{2}+\lambda_{n} \cdot w_{n},
$$

where $\lambda$ is the weight of a relevant criterion, and $w_{i}$ is a constituent criterion of the composite quality indicator.

When solving the optimisation problem, the absolute magnitudes of the coefficients $\lambda_{\mathrm{i}}$ were considered in proportion to the importance of a relevant partial criterion, taking into account their normalisation requirement: 


\section{$\left|\lambda_{1}\right|+\left|\lambda_{2}\right|+\left|\lambda_{n}\right|=1$}

In this study, the partial criteria of the composite quality indicator $Q_{\mathrm{f}}$ have different dimensions, and therefore a transition to dimensionless magnitudes took place according to the method (Pizhurin 2004, 2005) and based on Eq. 5,

$$
\omega_{i}=\left(W_{i}-W_{i} \min \right) /\left(W_{i} \max -W_{i} \min \right)
$$

where $W_{\text {imax }}$ and $W_{\text {imin }}$ are maximum and minimum values of the partial criterion $W_{\mathrm{i}}$.

Therefore, in its totality, the composite quality indicator of wood fibre semiproducts is an objective function, $Q_{\mathrm{f}}\left(F_{\mathrm{br}}, L_{\mathrm{a}} / d_{\mathrm{a}}, F_{\mathrm{m}}, L_{\mathrm{a}}, \mathrm{DS}\right) \rightarrow \max$.

\section{RESULTS AND DISCUSSION}

\section{Results of Solving the Optimisation Problem}

Based on many experiments, the optimisation results are presented below. In the results of processing the experimental data, a system of functional dependencies was obtained (Fig. 2), as well as graphical dependencies are presented (Figs. 3-4). Table 2 presents the results of statistical analysis of functional dependencies, confirming their adequacy and the possibility of practical application.

$$
\left\{\begin{array}{l}
D S=-140.78+26.7 \cdot g+22.563 \cdot Q_{d}\left(D S_{d}\right)+19.71 \cdot c-235 \cdot g^{2}-0.906 \\
Q_{d}\left(D S_{d}\right)^{2}-1.35 \cdot c^{2}+3 \cdot g \cdot Q_{d}\left(D S_{d}\right)-17 \cdot g \cdot c-0.7 \cdot Q_{d}\left(D S_{d}\right) \cdot c \\
F b r=-1167.15+1048,25 \cdot g+183.042 \cdot Q_{d}\left(D S_{d}\right)+91.585 \cdot c-5607.5 \\
g^{2}-7.564 \cdot Q_{d}\left(D S_{d}\right)^{2}-5.675 \cdot c^{2}+10,833 \cdot g \cdot Q_{d}\left(D S_{d}\right)-57,5 \cdot g \cdot c-3,583 \\
Q_{d}\left(D S_{d}\right) \cdot c \\
F_{m}=-30.57+29.45 \cdot g+12.142 \cdot Q_{d}\left(D S_{d}\right)-3.335 \cdot c-767.5 \cdot g^{2}-0.608 \cdot Q_{d}\left(D S_{d}\right)^{2}- \\
1.475 \cdot c^{2}+4.167 \cdot g \cdot Q_{d}\left(D S_{d}\right)+12.5 \cdot g \cdot c+1.15 \cdot Q_{d}\left(D S_{d}\right) \cdot c \\
L_{a}=-16,486+32,705 \cdot g+3,049 \cdot Q_{d}\left(D S_{d}\right)+0,665 \cdot c-90,675 \cdot g^{2}-0,135 \cdot \\
Q_{d}\left(D S_{d}\right)^{2}-0,257 \cdot c^{2}-1,175 \cdot g \cdot Q_{d}\left(D S_{d}\right)+2,585 \cdot g \cdot c+0,063 \cdot Q_{d}\left(D S_{d}\right) \cdot c \\
L_{a} / d_{a}=-1125,6+883,1 \cdot g+172,337 \cdot Q_{d}\left(D S_{d}\right)+112,41 \cdot c-5555 \cdot g^{2}-6,95 \\
Q_{d}\left(D S_{d}\right)^{2}+1,65 \cdot c^{2}+37 \cdot g \cdot Q_{d}\left(D S_{d}\right)-141 \cdot g \cdot c-6,7 \cdot
\end{array}\right.
$$

Fig. 2. System of functional dependencies

Table 2. Results of Statistical Analysis of Functional Dependencies

\begin{tabular}{|c|c|c|c|}
\hline parameter & F-test & st. dev. & $\mathrm{R}^{2}$ \\
\hline $\mathrm{DS}$ & 1.81 & 2.01 & 0.99 \\
\hline $\mathrm{Fbr}$ & 0.85 & 15.99 & 0.99 \\
\hline $\mathrm{F}_{\mathrm{m}}$ & 2.31 & 2.71 & 0.99 \\
\hline $\mathrm{L}_{a}$ & 1.67 & 0.56 & 0.99 \\
\hline $\mathrm{L}_{\mathrm{a}} / \mathrm{d}_{\mathrm{a}}$ & 2.17 & 15.10 & 0.99 \\
\hline
\end{tabular}


(a)

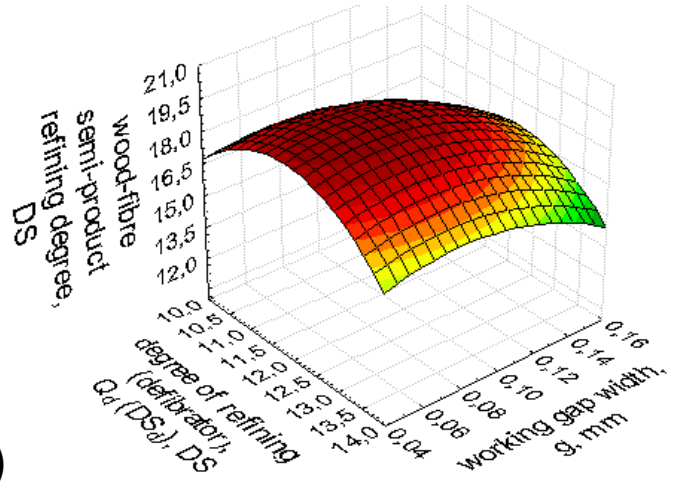

'b)

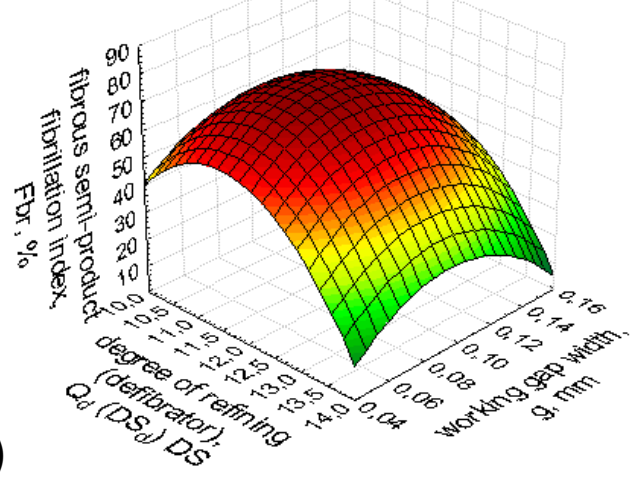

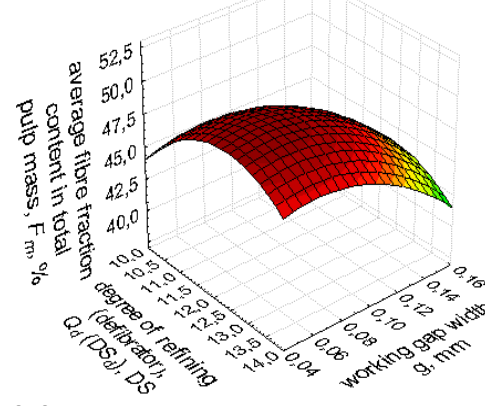

(c)

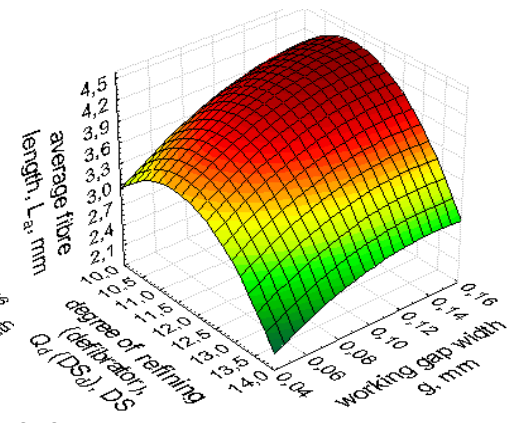

(d)

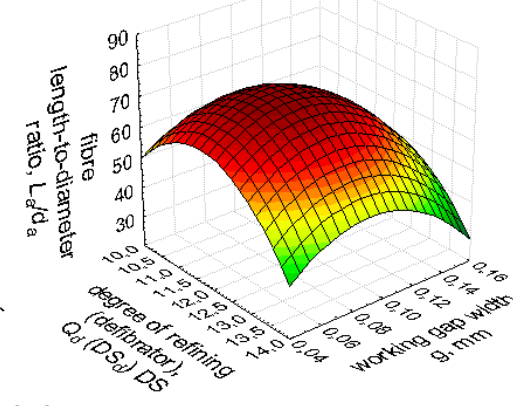

(e)

Fig. 3. The influence of the degree of refining after the defibrator and the working gap on the change in the main dimensional and qualitative characteristics of the semi-finished product (a-e)

(a)

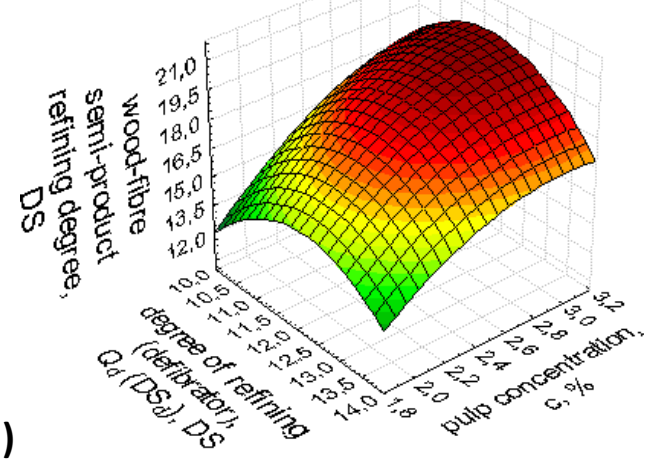

(b)

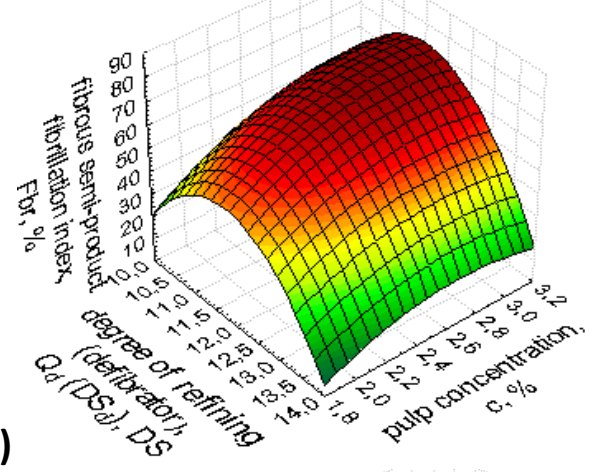

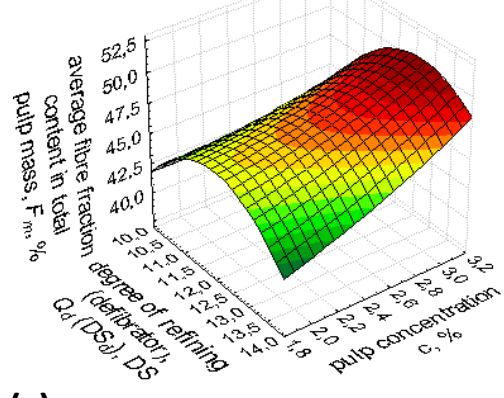

(c)

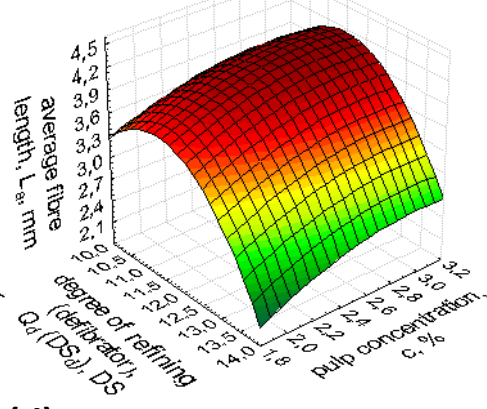

(d)

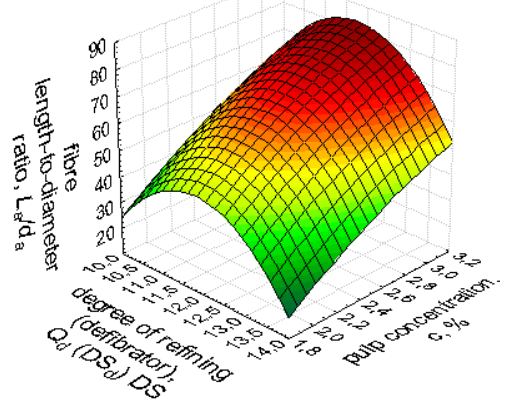

(e)

Fig. 4. The influence of the degree of refining after the defibrator and pulp concentration on the change in the main dimensional and qualitative characteristics of the semi-finished product (a-e) 
These dependencies are used to establish the values of variable parameters within the range of their variation, at which the greatest efficiency of the refining process and the best preset values of the dimensional and qualitative characteristics of semi-finished products providing the necessary quality of finished boards corresponding to GOST 4598 (2018), EN 622 (2004) are achieved, while minimising the specific power consumption for refining.

To solve the problem, a mathematical model was built in which the refining efficiency characterised by the composite quality indicator of wood fibre semi-finished products (the requirement of which is to strive for max) was chosen as the objective function $(f)$. The work has a system of restrictions on process parameters that vary within established limits, dimensional and qualitative characteristics of semi-finished products, and physical and mechanical properties of finished products according to GOST 4598 (2018), EN 622 (2004), as well as a condition for minimising the specific power consumption for refining.

The optimisation problem is a non-linear programming problem due to the complexity and unpredictability of the refining process. It was solved using Quasi-Newton methods and the STATISTICA-6 application package (Borovikov and Borovikov 1998). At the first stage, an electronic spreadsheet contains restrictions of process parameters related to the refining process that are determined by the design properties of refiner discs $E f_{r}\left(L_{\omega . e l}, L_{s}, t, F\right)$, mode parameters of the refining process $E f_{r}\left(Q_{d}\left(D S_{d}\right), g, c\right)$. Additionally, restrictions are introduced for the dimensional and qualitative characteristics $E f_{r}\left(F_{\mathrm{br}}, L_{a} / d_{a}, F_{m}, L_{a}, D S\right)$ of semi-finished products and the physical and mechanical properties of fibreboards $\left(\sigma_{i}, \rho, A\right)$.

The mathematical model of the problem of optimising the efficiency of the refining of wood fibre semi-finished products, taking into account new refiner disc geometry in fibreboard production, is shown in Fig. 5.

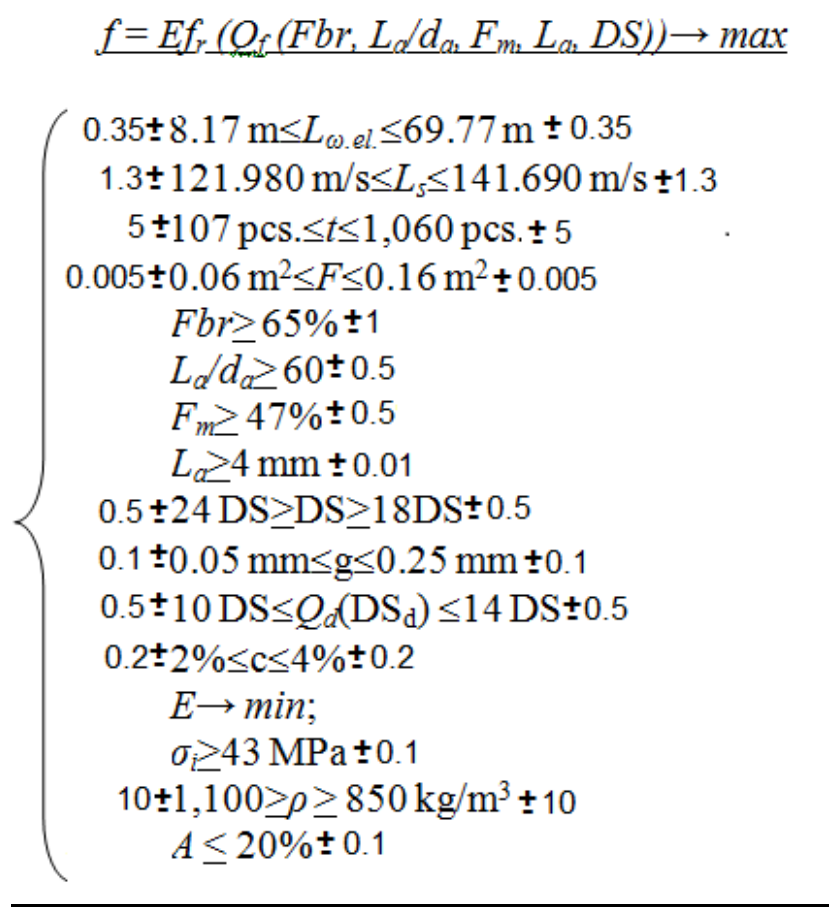

Fig. 5. Mathematical model of the problem of optimising the efficiency of the refining of wood fibre semi-finished products 
The solution to the optimisation problem using new refiner disc geometry produced the optimal values of process parameters characterising the high efficiency of the refining process as a whole, and to establish the optimal modes of wood fibre preparation, which for these production conditions will be: cyclic elementary length $-L_{\omega . e l}=15.65 \mathrm{~m}$, length of cuts per second $-L_{s}=136,450 \mathrm{~m} / \mathrm{s}$, number of contacts formed at the intersection of rotor and stator bars $-t=528 \mathrm{pcs}$, refining working surface $-F=0.06-0.1 \mathrm{~m}^{2}$, degree of wood fibre refining after defibrator $-Q_{d}\left(\mathrm{DS}_{\mathrm{d}}\right)=12 \mathrm{DS}$; working gap $-g=0.1 \mathrm{~mm}$; pulp concentration $-c=3 \%$. The physical and mechanical properties of boards are as follows: strength $-\sigma_{\mathrm{i}} \approx 45.2 \mathrm{MPa}$; density $-P \approx 938.2 \mathrm{~kg} / \mathrm{m}^{3}$; water absorption $-A \approx 16.9 \%$.

The established values of process parameters and the refining process modes provide optimal dimensional and qualitative characteristics of fibres that determine the quality indicator of semi-finished products $Q_{f}=0.7$ at the specific power consumption for the refining process $E=18 \mathrm{~kW} \cdot \mathrm{h} / \Delta \mathrm{DS} \cdot \mathrm{t}$.

Figure 6 shows photographs illustrating the efficiency of the wood fibre refining process.

(a)

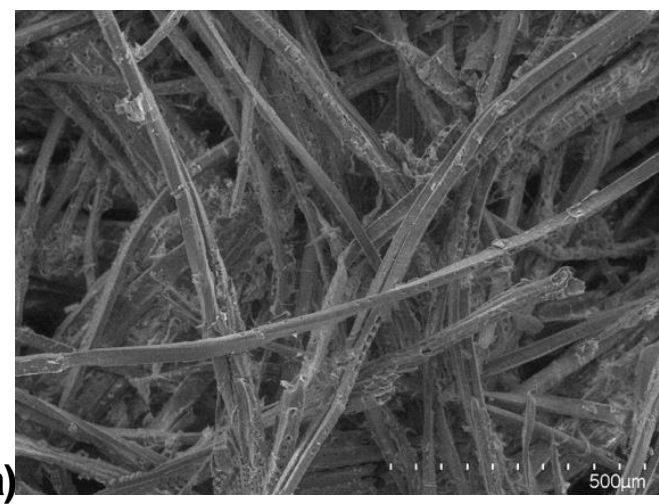

(b)

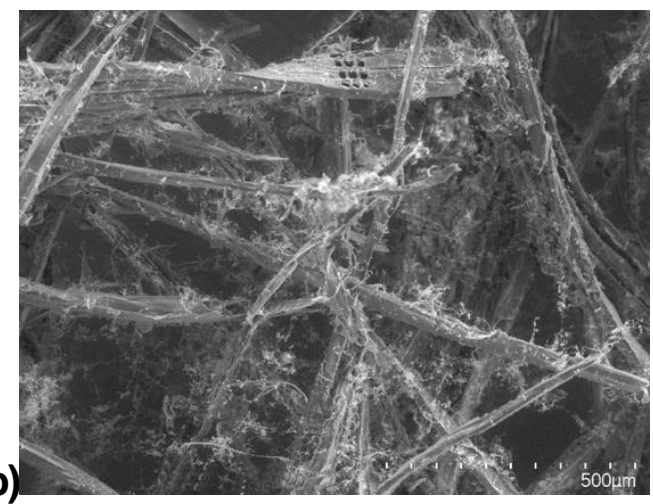

Fig. 6. Microscopic view of wood fibres (100x magnification) obtained before optimising the refining process using the traditional refiner disc geometry (a) and after optimising the refining process using new refiner disc geometry (b) $500 \mu \mathrm{m}$

Figure $6 \mathrm{~b}$ shows that after optimising the refining process using new refiner disc geometry, the composition of semi-finished products and the dimensional and qualitative characteristics of fibres were significantly improved $\left(\mathrm{DS}=20.2 \mathrm{DS} ; F_{\mathrm{br}}=80 \% ; L_{\mathrm{a}}=4.29\right.$ $\left.\mathrm{mm} ; L_{\mathrm{a}} / d_{\mathrm{a}}=93.3 ; F_{\mathrm{m}}=49.7 \%\right)$, giving rise to an increase in the quality indicator of semifinished products $\left(Q_{f}=0.7\right)$, in comparison with wood fibres $\left(Q_{f}=0.17: \mathrm{DS}=18 \mathrm{DS} ; F_{\mathrm{br}}\right.$ $=32 \% ; L_{\mathrm{a}}=5.1 \mathrm{~mm} ; L_{\mathrm{a}} / d_{\mathrm{a}}=35 ; F_{\mathrm{m}}=25 \%$ ) obtained before optimisation using the traditional refiner disc geometry (Fig. 6a). Improvement of the wood fibre quality indicates the high efficiency of the refining process. This occurs as a result of fibre breaking mainly in the longitudinal direction (fibrillation), thereby ensuring their flexibility, good bonding between fibres and, consequently, an increase in the fibreboard strength without bonding resins.

The composite quality indicator of wood-fibre semi-finished products $Q_{f}$ takes three ranges of values determining finished product quality: according to GOST 4598 (2018), EN 622 (2004) boards (Groups A and B), as well as ones (Group A) with increased strength: boards (Group B) is $0<Q_{f}<0.32$; boards (Group A) is $0.33<Q_{f}<0.66$; boards (Group A) with increased strength is $0.67<Q_{f}<1$. 
When analysing the quality characteristics that make up $Q_{f}$, it is worth noting that a decrease in the values of some characteristics within certain limits can be compensated by an increase in the values of other more significant ones, while generally maintaining the quality of wood-fibre semi-products and the physical and mechanical properties of finished products.

In general, refining optimisation using new refiner disc geometry will decrease the specific energy intensity of the refining process by $21 \pm 3.4 \%$ compared to the existing refiner operation modes (Vititnev 2019).

Based on the solution to the problem of increasing refining efficiency, it is proposed to use new refiner disc geometry and the results of the studies conducted under fibreboard production conditions. From calculations, summary tables were built to include all the main process, structural and power parameters of refiners, the geometric indicators of wood fibres, and the physical and mechanical properties of fibreboards.

Therefore, when varying refiner design and process parameters, it is possible to predict the necessary characteristics of semi-finished products and the indicators of finished fibreboards with minimal power consumption.

\section{CONCLUSIONS}

1. The solution to the problem of optimising wood fibre refining taking into account the new refiner disc design in fibreboard production made it possible to establish optimal values of process parameters and refining modes providing high refining efficiency in softwood preparation.

2. The new refiner disc geometry compared to traditional discs, with all other refining conditions being the same, ensures the preferential breaking of wood fibres in the longitudinal direction while maintaining their length. Optimising the refining process and effectively breaking the fibres doubles their length-to-diameter ratio and improves their flexibility. The content of long and thin fibrillated fibres in the total mass of semifinished products increases up to $50 \%$. Fibre qualitative characteristics and the fractional composition as a whole are improved, thereby providing high values of the quality indicator of semi-finished products and, consequently, the strength properties of finished products.

3. The optimal dimensional and qualitative characteristics of softwood fibres ensuring good interfibre interaction and eco-friendly board production (without bonding agents) are established in accordance with GOST 4598 (2018), EN 622 (2004), boards (Group A, grade I), with lower power consumption during refining.

\section{ACKNOWLEDGEMENTS}

The authors express their gratitude to the Centre for Collective Use of KSC SB RAS for supporting their research. This work was carried out under the State Assignment issued by the Ministry of Education and Science of Russia for the project: "Technology and Equipment for the Plant Biomass Chemical Processing" by the Plant Material Deep Conversion Laboratory (Subject No. FEFE-2020-0016). 


\section{REFERENCES CITED}

Alashkevich, Yu., Kovalev, V., and Nabieva, A. (2010). Tool Pattern Effect on the Fibrous Material Milling Process: Monograph in Two Volumes. Volume 1, Siberian State Technological University, Krasnoyarsk, Russia.

Ammar, M., Mechi, N., Hidouri, A., and Elaloui, E. (2018). "Fiberboards based on filled lignin resin and petiole fibers," Indian Academy of Wood Science 15(2), 120-125.

Badin, N., Campean, M., Lengyel, K., Ispas, M., and Bedelean, B. (2018). "Property improvement of thin high-density fiberboard panels used as door-skins," BioResources 13(1), 1042-1054. DOI: 10.15376/biores.13.1.1042-1054

Balmasov, E. A. (1979). Research and Development of Technological Foundations for the Production of Fiberboard with the Aim of its Optimization, Ph.D. Dissertation, Moscow Forestry Institute, Moscow, Russia.

Benthien, J. T., Heldner, S., and Ohlmeyer, M. (2017). "Investigation of the interrelations between defibration conditions, fiber size and medium-density fiberboard (MDF) properties," Eur. J. Wood Prod. 75(2), 215-232. DOI 10.1007/s00107-016-1094-2

Berg, J.-E., Gulliksson, M. E., and Gradin, P. A. (2009). "On the energy consumption for crack development in fibre wall in disc refining - A micromechanical approach," Holzforschung 63, 204-210.

Bordin, R., Roux, J. C., and Bloch, J. F. (2007). "Global description of refiner plate wear in low consistency beating," Nord. Pulp Pap. Res. J. 22(4), 529-534 DOI: 10.3183/npprj2007-22-04-p529-534

Bordin, R., Roux, J.-C., and Bloch, J.-F. (2008). "New technique for measuring clearance in low-consistency refiners," Appita Journal 61, 71-77.

Borovikov, V. P., and Borovikov, I. P. (1998). STATISTICA. Statistical Analysis and Data Processing in Windows, Filin Inf.-Publ. House, Moscow, Russia.

Cai, H., Yuan, Z. Y., Tong, G. L., Zhang, X., and Zhang, H. (2020). "Comparison of two bar edge lengths of refining plates on the properties of American old corrugated container pulp during low consistency refining," BioResources 15(1), 347-359. DOI 10.15376/biores.15.1.347-359

Chistova, N. G. (2010). Recycling Wood Waste in Fiberboard Production, Ph.D. Dissertation, Siberian State Technological University, Krasnoyarsk, Russia.

Dickson, A., Thumm, A., Murton, K., and Squist, D. (2020). "The influence of mechanical pulping treatment on the physical properties of wood fibre plastic composites," BioResources 15(3), 5532-5545. DOI 10.15376/biores.15.3.5532-5545

EN 622 (2004). "Fibreboards. Specifications. Part 2: Requirements for hardboards, NEQ", European Committee for Standardization, Brussels, Belgium.

Fernandez, F. J., Martinez, D. M., and Olson, J. A. (2018). "Investigation of low consistency reject refining of mechanical pulp for energy savings," Nord. Pulp Pap. Res. J. 33(1), 21-27. DOI: 10.1515/npprj-2018-3006

Ferritsius, O., Ferritsius R., and Rundlof, M. (2018). "Average fibre length as a measure of the amount of long fibres in mechanical pulps - ranking of pulps may shift," Nord. Pulp Pap. Res. J. 33(3), 468-481. DOI: 10.1515/npprj-2018-3058

Fredrikson, A., and Paltakari, J. (2020). "Maximizing pulp output and quality through measurement of plate gap temperature in high-consistency refining," BioResources 15(2), 2258-2278. DOI 10.15376/biores.15.2.2258-2278

Gao, Z., Wang, X., Wan, H., and Brunette, G. (2011). "Binderless panels made with black spruce bark," BioResources 6(4), 3960-3972. 
Gao, Y., Hua, J., Chen, G., Cai, L., Jia, N., and Zhu, L., (2018). "Prediction of fiber quality using refining parameters in medium-density fiberboard production via the support vector machine algorithm," BioResources 13(4), 8184-8197. DOI 10.15376/biores.13.4.8184-8197

Goncharov, V. (1990). Theoretical Basis for Fibrous Material Milling in Knife Machines, Ph.D. Dissertation, Leningrad, USSR.

GOST 4598 (2018). "Fibre boards by wet way of production. Specifications," Moscow, Russia.

GOST 10633 (2018). "Fiberboards. Test Methods," Moscow, Russia.

Gurau, L., Ayrilmis, N., Benthien, J. T., Ohlmeyer, M., Kuzman, M. K., and Racasan, S. (2017). "Effect of species and grinding disc distance on the surface roughness parameters of medium density fiberboard," Eur. J. Wood Prod. 75(3), 335-346. DOI 10.1007/s00107-016-1081-7

Hua, J., Chen, G. W., Xu, D. P., and Shi, S. Q. (2012). "Impact of thermomechanical refining conditions on fiber quality and energy consumption by mill trial," BioResources 7(2), 1919-1930.

Huber, P., Carre, B., and Petit-Conil, M. (2008). "The influence of TMP fibre flexibility on flocculation and formation," BioResources 3(4), 1218-1227.

Ihnat, V., Lubke, H., Boruvka, V., and Russ, A. (2017). "Waste agglomerated wood materials as a secondary raw material for chipboards and fibreboards. Part I: Preparation and characterization of wood chips in term of their reuse," Wood Research 62(1), 45-56.

Ihnat, V., Lubke, H., Russ, A., Pazitny, A., and Boruvka, V. (2018). "Waste agglomerated wood materials as a secondary raw material for chipboards and fibreboards. Part II. Preparation and characterisation of wood fibres in terms of their reuse," Wood Research 63(3), 431-442.

Ihnat, V., Lubke, H., Balbercak, J., and Kuna, V. (2020). "Size reduction downcycling of waste wood. Review," Wood Research 65(2), 205-220.

Irle, M., Privat, F., Couret, L., Belloncle, C., Deroubaix, G., Bonnin, E., and Cathala, B. (2018). "Advanced recycling of post-consumer solid wood and MDF," Wood material Science \& Engineering 14(1), 19-23.

Kerekes, R. (2011). "Force-based characterization of refining intensity," Nord. Pulp Pap. Res. J. 26(1), 14-20. DOI: 10.3183/npprj-2011-26-01-p014-020

Kovalev, V. (2007). "Milling fibrous semi-finished materials under different knife arrangement patterns," Ph.D. Dissertation, Siberian State Technological University, Krasnoyarsk, Russia

Kozhukhov, V. (2015). Milling Fibrous Semi-finished Materials in the Milling Knife Machines by Fiber Beating, Ph.D. Dissertation, Siberian State Technological University, Krasnoyarsk, Russia

Laskeev, P. K. (1967). Wood Pulp Production, Lesnaya Promyshlennost, Moscow, Russia.

Li, B., Li, H. M., Zha, Q. Q., Bandekar, R., Alsaggaf, A., and Ni, Y. H. (2011). "Review: Effects of wood quality and refining process on TMP pulp and paper quality," BioResources 6(3), 3569-3584

Li, Z., Qi, X., Lan, S., Wang, H., Chen, N., Lin, J., Lin, M., and Rao, J. (2019). "Optimizing properties of ultra-low-density fiberboard via response surface methodology and evaluating the addition of a coupling agent," BioResources 14(2), 4373-4384. DOI 10.15376/biores.14.2.4373-4384 
Liu, H., Dong, J. X., Jing, H., Guo, X. Y., Duan, C. W., Qi, K., Yang, R. F., Guo, H. Z., Wang, B., and Qiao, L. J. (2020). "Refining characteristics of isometric straight bar plates with different bar angles," BioResources 15(4), 7844-7860. DOI 10.15376/biores.15.4.7844-7860

Lubke, H., Ihnat, V., and Boruvka, V. (2014). "Straw pulp as a secondary lignocellulosic raw material and its impact on properties of properties of insulating fiberboards. Part I. Characteristic of straw fibre from the perspective of the mass creation," Wood Research 59(5), 747-755.

Mancera, C., El Mansouri, N. E., Vilaseca, F., Ferrando, F., and Salvado, J. (2011). "The effect of lignin as a natural adhesive on the physico-mechanical properties of Vitis vinifera fiberboards," BioResources 6(3), 2851-2860.

Matygulina, V., Rubinskaya, A., Chistova, N., and Alashkevich, Yu. (2011). "Selection of optimum modes of the technological process of production of medium density fiberboard," Khimiya Rastitel'nogo Syr'ya 4 2011, 315-317.

Mersov, E. D. (1989). Fiberboard Production. Higher School, Moscow, Russia.

Min, B. G., Lee, J. Y., Kim, C. H., Park, S. H., Lee, M. S., Gu, H. G., and Lee, C. Y. (2020). "New technology for developing a lightweight refiner plate for hardwood kraft pulp fibers," BioResources 15(4), 9128-9142. DOI 10.15376/biores.15.4.9128-9142

Muller, G., Schopper, C., Vos, H., Kharazipour, A., and Polle, A. (2009). "FTIR-ATR spectroscopic analyses of changes in wood properties during particle- and fibreboard production of hard- and softwood trees," BioResources 4(1), 49-71.

Nabieva, A. A, Nesterov, E. E., Alashkevich, Y. D., and Karpenko, D. S. (2009). Numerical Method for Determining the Second Cutting Length of a Sector Knife Set of Disk Mills with Parallel Rectilinear Blades of Constant Width (Certificate No. 2009613683 RF/. - No. 2009612514), Siberian State Technological University, Krasnoyarsk, Russia.

Nabieva, A. (2004). Assessing the Efficiency and Technological Improvement of the Knife Milling Machines, Ph.D. Dissertation, Siberian State Technological University, Krasnoyarsk, Russia

Olejnik, K. (2013). "Impact of pulp consistency on refining process conducted under constant intensity determined by SEL and SEC factors," BioResources 8(3), 32123230 .

Park, S. H., Lee, M., Seo, P. N., and Kang, E. C. (2020). "Effect of resin content on the physiochemical and combustion properties of wood fiber insulation board," BioResources 15(3), 5210-5225. DOI 10.15376/biores.15.3.5210-5225

Pelletier, A., Zhao, Y., Lei, XC., and Li, K. C. (2013). 'Improved fiber separation and energy reduction in thermomechanical pulp refining using enzyme-pretreated wood," BioResources 8(3), 3385-3398.

Pen, R. Z., and Mencher, E. M. (1978). Statistical Methods in Paper Production, Forest Industry, Moscow, Russia.

Pizhurin, A. A. (2004). Modeling and Optimization of Woodworking Processes, MGUL Moscow State University of Forestry, Moscow, Russia.

Pizhurin, A. A. (2005). Scientific Research Foundations, MGUL Moscow State University of Forestry, Moscow, Russia.

Przybysz, P., Dubowik, M., Malachowska, E., Kucner, M., Gajadhur, M., and Przybysz, K. (2020). "The effect of the refining intensity on the progress of internal fibrillation and shortening of cellulose fibers," BioResources 15(1), 1482-1499. DOI 10.15376/biores.15.1.1482-1499 
Rusu, M., Liukkonen, S., Gregersen, O., and Sirvio, J. (2011). "The influence of fibre wall thickness and fibril angle on fibre development in the TMP process," Nord. Pulp Pap. Res. J. 26(1), 6-13. DOI: 10.3183/npprj-2011-26-01-p006-013

Sable, I., Grinfelds, U., Vikele, L., Rozenberga, L., Zeps, M., Neimane, U., and Jansons, A. (2017). "Effect of refining on the properties of fibres from young Scots (Pinus sylvestris) and lodgepole pines (Pinus contorta)," Baltic Forestry 23(2), 529-533.

Smith, S. (1992). Die rationelle Theorie das Ganzzeughollandar, Otto Ernst Verlag, Teil I, Berlin.

Song, W., Zhu, M., Lin, W., and Zhang, S. (2018). "Determining optimum material mixture ratio and hot-pressing parameters for new hybrid fiber-reinforced composites: Modeling and optimization by response surface methodology," BioResources 13(2), 4202-4223. DOI: 10.15376/biores.13.2.4202-4223

Somboon, P., Nieminen, K., and Paulapuro, H. (2008). "Finite element analysis of the fatigue behavior of wood fiber cell walls," BioResources 3(4), 983-994.

Vikharev, S. (2019). "Research of a fibrous layer at refining in the refiners," IOP Conf. Series: Earth and Environmental Science 316: 012080

Vititnev, A. Yu. (2019). Improving the Fibrous Semi-finished Material Milling in the Fiberboard Production Process, Ph.D. Dissertation, Reshetnev Siberian State University. Krasnoyarsk, Russia

Zhang, H. J., Li, Z. Q., Yang, S., Zhang, W. H., Sun, Y., Chen, S. H., and Luo, C. (2019). "Comparison of some key parameters contributing to lignocellulosic fiber deformation behavior by a mathematical model," BioResources 14(2), 4136-4145. DOI 10.15376/biores.14.2.4136-4145

Zhao, X. P., Guo, P. P., Zhang, Z. L., Wang, X. C., Peng, H. X., and Wang, M. K. (2018). "Wood density and fiber dimensions of root, stem, and branch wood of Populus ussuriensis Kom. Trees," BioResources 13(3), 7026-7036.

Zyryanov, M. A. (2012). Producing Semi-finished Materials in One Milling Stage for Fiberboard Production with the Moist Method, Ph.D. Dissertation, Siberian State Technological University, Krasnoyarsk, Russia.

Article submitted: August 18, 2021; Peer review completed: September 13, 2021;

Revised version received and accepted: September 29, 2021; Published: October 4, 2021. DOI: 10.15376/biores.16.4.7751-7766 